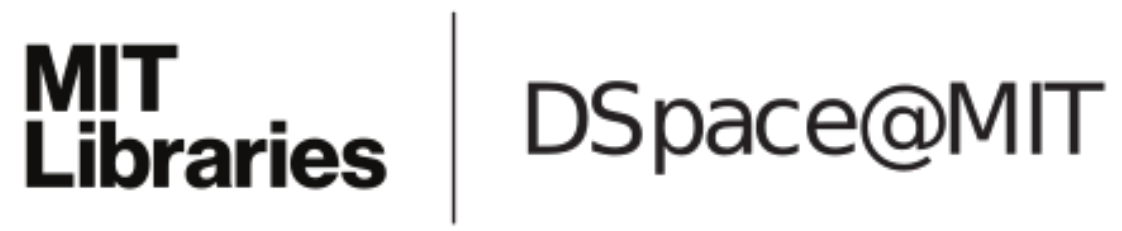

\author{
MIT Open Access Articles
}

Examining the Influence of Solar Panel Installers on Design Innovation and Market Penetration

The MIT Faculty has made this article openly available. Please share how this access benefits you. Your story matters.

Citation: Sinitskaya, Ekaterina, Kelley J. Gomez, Qifang Bao, Maria C. Yang, and Erin F. MacDonald. "Examining the Influence of Solar Panel Installers on Design Innovation and Market Penetration." Volume 2A: 43rd Design Automation Conference (August 6, 2017).

As Published: http://dx.doi.org/10.1115/DETC2017-68338

Publisher: ASME International

Persistent URL: http://hdl.handle.net/1721.1/120052

Version: Final published version: final published article, as it appeared in a journal, conference proceedings, or other formally published context

Terms of Use: Article is made available in accordance with the publisher's policy and may be subject to US copyright law. Please refer to the publisher's site for terms of use. 


\section{EXAMINING THE INFLUENCE OF SOLAR PANEL INSTALLERS ON DESIGN INNOVATION AND MARKET PENETRATION}

\author{
Ekaterina Sinitskaya \\ Postdoctoral Scholar \\ Mechanical Engineering \\ Stanford University \\ Stanford, CA, USA \\ katesini@stanford.edu
}

\author{
Kelley J. Gomez \\ Undergraduate Student \\ Mechanical Engineering \\ Stanford University \\ Stanford, CA, USA \\ kjgomez@stanford.edu
}

\author{
Qifang Bao \\ Graduate Student \\ Mechanical Engineering \\ Massachusetts Institute \\ of Technology \\ Cambridge, MA, USA \\ qfbao@mit.edu
}

\author{
Maria C. Yang \\ Associate Professor \\ Mechanical Engineering \\ Massachusetts Institute \\ of Technology \\ Cambridge, MA, USA \\ mcyang@mit.edu
}

\author{
Erin F. MacDonald \\ Assistant Professor \\ Mechanical Engineering \\ Stanford University \\ Stanford, CA, USA \\ erinmacd@stanford.edu
}

\section{ABSTRACT}

This work uses an agent-based model to examine how installers of photovoltaic (PV) panels influence panel design and the success of residential solar energy. It provides a novel approach to modelling intermediary stakeholder influence on product design, focusing installer decisions instead of the typical solar stakeholder foci of the final customer (homeowners) and the designer/manufacturer. Installers restrict homeowner choice to a subset of all panel options available, and, consequentially, determine medium-term market dynamics in terms of quantity and design specifications of panel installations. This model investigates installer profitmaximization strategies of exploring new panel designs offered by manufacturers vs. exploiting market-tested technology. Manufacturer design decisions and homeowner purchase decisions are modeled. Realistic details provided from installer and homeowner interviews are included. For example, installers must estimate panel reliability instead of trusting manufacturer statistics, and homeowners make purchase decisions based in part on installer reputation. We find that installers pursue new and more-efficient panels over sticking-with market-tested technology under a variety of panel-reliability scenarios and two different state scenarios (California and Massachusetts). Results indicate that it does not matter if installers are predisposed to an exploration or exploitation strategy-both types choose to explore new panels with higher efficiency.

\section{INTRODUCTION}

The United States (US) residential solar energy market is more than 20 years old and beginning to mature. US penetration rates have increased from virtually zero to 0.8 percent of all U.S. households in the past ten years [1]. With maturity comes new challenges, and the Department of Energy (DOE) has recognized the need for novel approaches to pushing penetration rates higher, for example studying solar installation as a social phenomenon via the SunShot Initiative [2]. If the growth rate declines from currently optimistic industry projections, solar installation and equipment businesses built on an assumption of constant growth will fail, as perhaps foreshadowed by the recent restructuring and acquisition of SolarCity by Tesla [3].

As the mechanical design community increasingly views products as systems, the design concerns of stakeholders in the system in addition to final consumers will receive increasing 
attention in research. This paper provides such an investigation for the residential PV market using an agent-based model to understand the design concerns of different stakeholders. Here, we investigate a system that includes manufacturing design and positioning installers' material-selection strategies with regard to the adoption of new technologies, and final consumer behavior.

This paper details the structure of the agent-based model and the rationale for the decisions made on what to include and exclude. Explanation of model calibration to create reasonable behavior for the US PV market is also provided. The work then makes a number of assumptions in order to examine some broad-level conclusions and recommendations for increasing PV adoption rates. Levers manipulated include: technical properties (panel efficiency), environmental factors (level of solar irradiation), and economic factors (income levels). Future follow up work will include detailed consumer and installer surveys and will provide new layers on the foundation the agent-based model presented in this paper. The main questions asked in this study are:

1. How are market outcomes shaped by different decision processes used by stakeholders? Specifically, how do panel installers decide what technologies to offer for sale?

In a typical consumer-driver product design problem, growth stagnation would be addressed by designing new features that drive consumer (homeowner) demand. However, due to the complex nature of a residential PV panel, other stakeholders, such as panel installers, may control adoption from a push standpoint, rather than homeowners controlling adoption from a pull standpoint. Chen et al. [4] discovered that solar installers make system design choices in the majority of instances, not homeowners. Here, instead of creating a detailed expression of end-customer needs, we simplify these needs and focus on a detailed expression of installer decisions and interactions with manufacturers and homeowners. We expect that this will identify new recommendations for improving panel adoption.

2. How does the strategy of installers influence the behavior of the model and change with time and environmental conditions?

In the model, installers can choose an exploration or exploitation strategy. The former is the risk-seeking behavior of choosing to sell a new technology, and the latter the risk-averse behavior of sticking with current offerings. Two scenarios represent a high level of solar irradiation with high PV penetration level, and a low level of solar irradiation with lower PV penetration level. We expect to reveal insights about stakeholder behavioral strategy changes in new and mature markets as defined by the solar PV penetration level; and under different environmental conditions, defined by the levels of solar irradiation.

The paper proceeds as follows: Section 2 reviews background information modeling efforts for PV market; Section 3 presents the simulation methods of decision processes modeling and engineering modeling; Section 4 presents the simulation results and discussion; and Sections 5 provides conclusions.

\section{BACKGROUND}

This paper does not focus on developing breakthrough technology for solar energy, but rather improving adoption with projections on currently-available equipment, for example, incremental increases in energy efficiency. For an overview of PV systems technology research see [5], and for improvements in manufacturing over the last decade see [6]. These studies discussed the efficacy of new processes, but the question remains: how does industry introduce new technologies and through what process do homeowners choose to adopt them?

Stakeholders in the residential PV market other than homeowners include manufacturers, installers, and regulatory agencies. Manufacturers produce equipment for PV systems. Installers configure systems to satisfy needs of customers and install them on houses. Regulatory agencies are responsible for permitting, such as building requirements and grid-connection requirements.

Research on residential solar PV adoption traditionally focuses on homeowners as final consumers of the product. But both Chen et al. [4] and interviews of installers conducted by the authors at the Intersolar North America 2016 conference confirmed that installers make product design choices and offer homeowners only a subset of all panels available on the market [7]. Thus, installers are also consumers, in a business-tobusiness relationship. They consume a manufacturer's product; they specialize in specific designs from a manufacturer's catalogue and offer a limited range of these selections to homeowners. As a result, manufacturers should direct their design efforts towards them as well as homeowners.

More "traditional" modeling research focuses on homeowners as final choice agents. For example, Karakaya and Sriwannawit [8] identified barrier-to-adoption issues such as the high price of PV systems, complexity of interaction between people and the PV system, and ineffective policy measures. Islam and Meade [9] found that an educational campaign for homeowners might be effective at increasing adoption rates. But there are other barriers to adopting the latest technology and PV systems beyond homeowner decisions. For example, installers must be willing to offer the latest technology for sale. Installers serve as gate-holders for the new developments that are created by PV system manufacturers. Installer's choices are governed by the desire to maximize profits and may not be perfectly aligned with the homeowners' preferences, the manufacturers' drive to push technology forward, or the government's goals for increasing adoption at a manageable rate.

While the installer's role in solar market dynamics is apparent, there is very little research into their actual decision patterns. Research concentrates on either general trends, such as report [1] which provided an overview of recent trends in market prices and volumes, or on modeling energy production, such as in $[10,11]$, which created detailed models of energy 
production that included renewable energy sources to assess impact on utility costs. Another example of this line of research is [12], where Janko, et al. focused on estimating effects on net loads under changing environmental factors. They found that the coverage area, direction, and time of day affected the net load differently. Frischknecht and Whitefoot created a static model that captures a single period of PV panel market sensitivities to changes in engineering parameters [13]. They found that an early-stage engineering design performance model could be incorporated into a decision framework. Chen, et al. [4] surveyed installers to determine preference information for residential solar panels and compared findings with past market data, but made no predictions for future behavior. We are exploring the role of installer choices in a working paper [7] using linked journey maps for installers and homeowners. We discover that installers' decisions regarding their portfolio of products frame homeowners' choices and effectively determine which technologies will be deployed on the market.

Installers face complex decisions, not only while choosing from a limited range of offered technologies, but also when designing a PV system for homeowners. To be able to predict the effects of their choices on a market with complex offerings that are tailored to specific homeowners, we need to explicitly model the distribution of technological and socio-economic parameters that may influence installers' choices.

One of the analytical tools that can achieve this level of detail is the agent-based model. An agent-based model is a simulation-based model that explicitly models individual agents' actions while also models the network of interactions and interdependencies between the agents. Simulation of the associated physical environment is customary. Agents can be both stakeholders on the market of relevant technological and physical properties. For a brief introduction to agent-based models, see [14]. Some of their advantages are an ability to capture multiple complex distributions and naturally modeling network interactions. The latter is an integral part of environmental considerations as argued in [15]. Agent-based models have been successfully used for evaluating demandoriented policies, for example, by [16-20]. Zhao, et al. [16] concentrated on the multi-level modeling of energy generation for solar-panels and consumer decisions that step from detailed estimation of possible energy production given their geographical characteristics. They concluded that sensitivity of homeowners to changes in incentives is different for different regions. Robinson and Rai expanded on spatial agent-based modeling for the analysis of PV systems adoption rates [17]. They concluded that agent-level behavior and social interactions are important for explaining patterns of adoption. For other examples of this line of work see [21]. Robinson and Rai brought together multiple social, economic and environmental factors into complex agent-based model to analyze penetration rates arising from homeowners' possible choices [17], suggesting that explicit modeling of agents characteristics is crucial for accurate policy analysis. However, none of this agent-based modeling work in solar adoption provided a high resolution articulation of the installer's role in the system, and we argue that this, in fact, underestimates the type and level of existing barriers to adoption.

An engineer reading this work may feel uncomfortable with the level of uncertainty, or lack of precision in the parameterization of the model presented below. The developed model aims to keep the minimum level of complexity that is required to explore installer decisions. Inclusion of socioeconomic elements in the form of installer and homeowner decisions inevitably leads to a highly probabilistic model. It is simply not possible to be as precise about how a person might behave as it is to be about the amount of electricity produced by a solar panel. This approach of studying trends is valuable and useful for learning about socio-technical models. There are other reasons, such as the high level of unpredictability of the research process into new PV panels, that a probabilistic and trend-like model is needed. Note that this is not an optimization study that recommends one final design outcome. Instead, trends and changes of trends under model manipulations are reported for discussion and conclusion.

\section{MODEL DESCRIPTION \\ 3.1 General Flow of the Model}

The dynamic agent-based model represents simulated market dynamics for a number of years. The simulation is run for a fixed number of steps, each step representing approximately one year of actual time. This section provides an overview of important agent actions, with more-detailed descriptions given in the sections to follow. The overall flow of the model is described in Figure 1. Each agent in the model has a different goal. Manufacturers, represented by an icon of a factory, play a passive role in this model, representing exogenous technological progress. Homeowners, represented by a house icon, evaluate the financial viability of investing in PV systems given their specific set of parameters. Government decisions are not directly modeled, but instead are embedded in the pricing structure of the panels (current incentive structuring is modeled).

The model focuses on installer decision behavior. At the start of each year (model step), installers choose what equipment to use in their installation bids to homeowners. Installers can choose to keep using their current technology or explore new options and switch to another design from the same or potentially new manufacturer. Some installers are more inclined toward exploration of existing offerings on the market; others are more likely to keep using their current design; and others may even switch to a new technology if the expected gain from switching is high enough. After an installer settles on a specific design, she customizes it to the homeowner needs, creating a specific PV system for the electricity demand level and house size. 


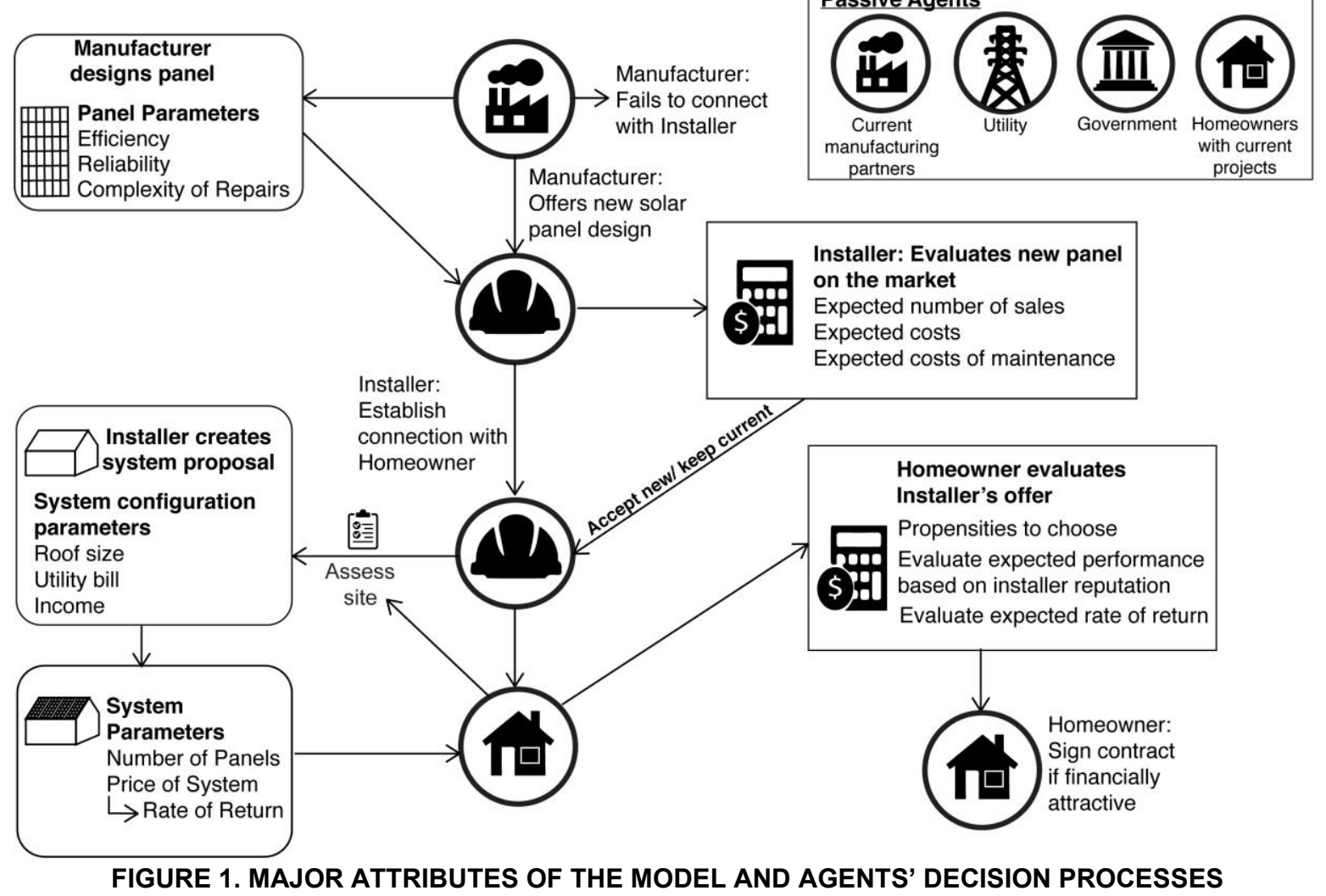

Available technologies for PV modules differ in their efficiency levels and reliability. The efficiency of the panel is its ability to convert a given amount of solar energy into electricity per square meter and is immediately known to everyone. The reliability, or probability of experiencing a break-down during deployment period, is revealed after the projects are deployed. Reliability in-part determines the production of energy for each project per year, if the system goes down it will require maintenance for a period of time, and it will not generate electricity for this time.

Manufacturers price their current panel offerings on their expected efficiency. As the time goes by, manufacturers invest in research and development to improve the efficiency of their panels in a gradual manner. As they do not focus on improving reliability, it may either decrease or increase per model step.

A fixed portion of all homeowners respond to marketing information during each year and decide to accept or reject installation offers from installers, depending on the offered rate of return of investment and the reputation of the installers they consider.

Generally, manufacturers have access to actual performance information for PV panels. Installers have to rely on their field observation of the performance. They also have estimates of homeowner's demand. Homeowners can only observe the reputation of installers and do not have access to raw efficiency and reliability data. A summary of availability of the information to each party is given below in Figure 2.

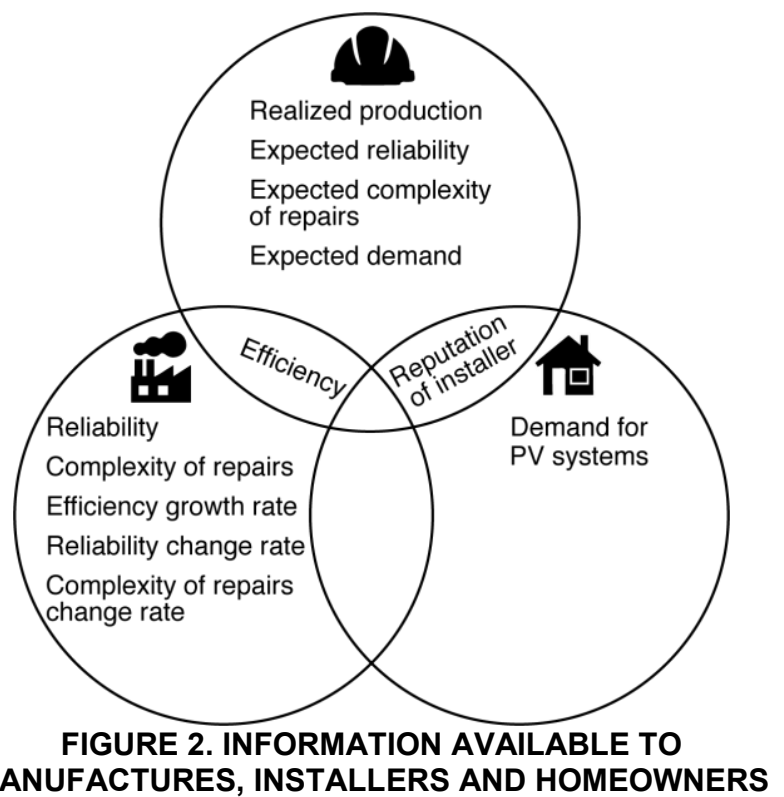

The model was tested under two different scenarios corresponding to different cities within the US. General parameters of the agent-based model were set to represent two distinct local environments: CA scenario San Jose, California with high levels of solar irradiation and PV system penetration set at 5\%; and MA scenario Massachusetts, with lower levels 
of solar irradiation and PV penetration at $0.5 \%$. Levels of irradiation were set to $4.0 \mathrm{kWh} / \mathrm{m}^{2} /$ Day for MA and 6.0 for CA, taken from [22]. Other scenarios with varying levels of solar irradiation and PV system penetration are possible, but the choice was made to explore two different and realistic scenarios.

In the following sections, we will provide details of the decision process for installers, manufacturers, and homeowners.

\subsection{Installer's decision process}

Intelligent learning agents [14] are the best approach for modeling installers within an agent-based model, as they allow a way to represent constantly facing the decision and benefits/risks of changing PV offerings. Intelligent learning agents are agents that are allowed to update their beliefs in response to the observed dynamics of the environment.

There are different approaches to modeling decision process for intelligent learning agents. Wilson and Dowlatabadi [23] provided an overview of existing approaches in the field of environmental research. In the case of installers, a reasonable choice is profit maximization. It is an appropriate decision procedure for learning agents in a highly volatile environment, as argued in [24]. The amount of information installers get from serving already installed PV systems allows for the use of Bayesian methods. As installers observe the actual output of the installed systems, they can update their estimates of reliability of the panel. Bayesian methods are used to provide a way of combining their initial guesses regarding reliability of the PV system and the observed data.

Research into Bayesian learning effectively captures the learning dynamic $[25,26]$. Details of the implemented learning techniques are standard and can be found in [27]. While operating on the market, installers are constantly presented with new information that they incorporate into their decision process. We capture these features in our agent-based model by allowing installers to update their expectations after observing market outcomes of their decisions.

We allow installers to pursue different decision processes that can be either explorative or exploitive. The former assumes that agents are more open to exploring new options if it seems that it might be beneficial to them. The later strategy describes agents that are less inclined to explore new options and prefer to stay with their current choices for longer. The exploration vs exploitation question has traditionally been a key part of learning. The classical approach uses multi-armed bandits, as explained in [28]. A multitude of methods for reinforcement learning are described in [29]. Experiments show that in conditions when the learning environment is not extremely noisy it is plausible to assume that people use dynamic optimization with Bayesian learning to arrive at optimal strategies for exploration versus exploitation [30], and this is the approach used here. We extend analysis to the case of applied problem solving in a distributed agents environment.

\subsubsection{An Installer's PV module and Pricing Decisions}

Each installer has only one panel that they offer to homeowners. During every simulation step, each installer investigates replacing their current offering with a randomlyselected PV module that is available from manufacturers. Whether or not they decide to adopt a new PV module depends on their propensity to explore (rather than exploit). If they decide to adopt, they estimate the expected profit of PV system designs for the panel under consideration. Expected profit is determined by expected revenue minus the costs of services. The former depends on the installation price that the installer decides to offer during each step. Next, we will describe this decision process in detail.

Installers maximize their profit given the specific PV panel that they are offering as a basis for their design.

$$
\max _{\text {price }} \Pi_{t}
$$

The expected profit at time $\mathrm{t}$ is calculated over the forecasting horizon $T_{\text {forecast }}$ :

$$
\begin{aligned}
\Pi_{t}=\sum_{\tau=0}^{\tau=T_{\text {forecast }}} q_{t+\tau}(\text { price }) \text { price }- \\
\\
C_{t+\tau}\left(p(\text { maintenance }),\{q\}_{T_{0}}^{t+\tau}\right)
\end{aligned}
$$

where demand $q_{t+\tau}$ (price) $=q$ is estimated based on the offered rate of return and reputation of the installer. We will first explain this term in detail and then the cost term, $C$. Simple specification in the form of linear regression is used

$$
q=\left(\mathbf{z}_{\text {inst }} \boldsymbol{\theta}^{d}+\epsilon\right) \mathrm{N}_{\text {market }}
$$

where $Z_{\text {inst }}=\left[\mathbf{z}_{\text {inst }, t}\right]$ is the collection of observations at time $t$ that is used in sequential updating of Bayesian estimates of regression coefficients. $\boldsymbol{z}_{\text {inst }, t}$ includes the main demand parameters that influence homeowner choice: internal rate of return for installer $i$, its reputation $r e p_{i}$, internal rate of return (irr) of other installers $i r r_{-i}$, and reputation of other installers (excluding installer $i$ ) $r e p_{-i}$. irr is calculated in the standard way.

$$
\mathbf{z}_{\text {inst }, t}=\left[1, \operatorname{irr}_{i, t}, \operatorname{rep}_{i, t}, \operatorname{irr}_{-i, t}, \operatorname{rep} p_{-i, t}\right]
$$

$\boldsymbol{\theta}^{d}$ are regression coefficients for estimated demand. They are assumed to be randomly distributed. Bayesian prior on $\boldsymbol{\theta}^{d}$ is assumed to be Normal-Inverse-Gamma.

$$
\begin{gathered}
p\left(\boldsymbol{\theta}^{d}\right)=p\left(\boldsymbol{\theta}^{d} \mid \sigma^{2}\right) p\left(\sigma^{2}\right) \\
=N\left(\boldsymbol{\mu}_{\theta}, V_{\theta}\right) \times \operatorname{IG}\left(a_{d}, b_{d}\right)=\operatorname{NIG}\left(\boldsymbol{\mu}_{\theta}, V_{\theta}, a_{d}, b_{d}\right)
\end{gathered}
$$

Under these assumptions, the posterior predictive distribution is $\operatorname{MVSt}_{2 \alpha^{*}}\left(\boldsymbol{\mu}^{*}, \frac{b_{d}{ }^{*}}{a_{d^{*}}}\left(1+\tilde{Z} V^{*} \tilde{Z}^{T}\right)\right)$ (Multi-variate student distribution - MVS), the components of which are described in Appendix I. The mean of this distribution is used as a predictive: $\tilde{q}=\tilde{Z} \boldsymbol{\mu}^{*}$. Initial parameters are fixed at the levels (see Appendix I) that represent expectation of equal market shares for installers at the prevailing rates of return. 
Profit is maximized under an assumption of no labor and equipment constraints. This assumption is reasonable because the time horizon for maximizing the expected profit is five years, and one step in the model is equivalent to one year. Over these time intervals, installers can use a flexible amount of labor and equipment.

Now we will explain $C$ from Eq. (2). Equation (6) introduces all costs that are incorporated:

$$
\begin{gathered}
C_{t+\tau}\left(p,\{q\}_{T_{0}}^{t+\tau}\right)=c_{\text {installation }}+c_{\text {design }}+c_{\text {permit }} \\
+c_{\text {materials }}+c_{\text {administration }}+c_{\text {marketing }}+c_{\text {maintenance }}
\end{gathered}
$$

Installers have both fixed per period costs and variable costs. Variable costs depend on the size and specifications of each installation. Details of cost calculations are given in Eq. (7) - (13):

$$
\begin{gathered}
c_{\text {installation }}=\theta_{t, \text { complexity install }} \times w_{t} \times q \\
c_{\text {design }}=\theta_{\text {design }} \times w_{t} \times q \\
c_{\text {permit }}=\theta_{\text {permit general }} \times w_{t}+\theta_{\text {permit specific }} \times w_{t} \times q \\
c_{\text {materials }}=N_{\text {panels }} \times q \times \text { price }{ }_{\text {module }, \text { SEM }} \\
c_{\text {administration }}=\theta_{\text {administration }} \times w_{t} \\
c_{\text {marketing }}=\theta_{\text {marketing }} \times w_{t} \\
c_{\text {maintenance }}=f_{c}\left(\{q\}_{T_{0}}^{t+\tau}, p(\text { maintenance })\right)
\end{gathered}
$$

Maintenance costs in (13) depend on the expected probability of failure for the installed system $p$ (maintenance) and required labor costs to repair the systems $f_{c}\left(\{q\}_{T_{0}}^{t+\tau}, p\right.$ (maintenance) $)$. price module,SEM $_{\text {is }}$ is the price of a $\mathrm{PV}$ module that is determined by the module's manufacturer. $w_{t}$ is the prevailing labor wage at time t. $N_{\text {panels }}$ is the number of panels that is required by the specific design.

Other costs are fixed at levels that correspond to average costs of operating in the US residential PV market for a largescale installer, as reported in Appendix I. Values were calculated from SolarCity Corporation's financial reports for 2015. Each $\theta_{i}$ parameterizes part of overall costs as specified in Eq. (7)(13). For each time period $t+\tau$, where $t$ is current time period and $\tau$ is forecasting offset, total costs include all mentioned above parts as in Eq. (6). One of the parameters that defines a variable portion of the costs is $N_{\text {panels }}$. It is the number of solar modules that is required to be installed to provide enough electricity to the homeowner. In profit calculations, this number is calculated for an average homeowner, targeting one-hundred percent of their electricity consumption, under the assumption that there is enough physical space on the roof for the installations. It is also assumed that other conditions are favorable for installing PV panels. When the actual design is offered to the homeowner, roof size considerations will become part of the actual offer.

Exploration vs. Exploitation. Each installer has the option to switch to offering a new PV panel, untested in the market. The decision to switch is based on the expected difference in profit and the propensity to switch. The propensity to switch is specific to each installer, classified as either an explorer or exploiter. In this model simulation of three installers, one installer is assumed to be an explorer and the other two are exploiters.

The probability for switching $p_{\text {inst,switch }}$ is calculated using the logistic function:

$$
p_{\text {inst }, \text { switch }}=\frac{1}{1+\exp ^{-\frac{\frac{\Pi}{\text { new }}_{\text {old }}-\theta_{0, e}}{\theta_{1, e}}}}
$$

and parameter values $\theta_{i, e}$ are listed in Appendix I. Each set of parameters $\theta_{\{\text {explorer,exploiter }\}}$ (for explorer and exploiter) specifies propensity to switch to new design. $\Pi_{\text {old }}$ is calculated for expected maintenance, demand and efficiency of the current panel; $\Pi_{n e w}$ is calculated based on the expected maintenance for new panel and subject to the same demand estimations as the current panel.

\subsubsection{Installation and maintenance of PV panels}

Installation. The installer uses their currently-offered panel to create specifications for installation, given homeowner parameters. There are environmental parameters that are fixed for all agents and all simulations such as level of solar irradiation and difficulty in acquiring permits. There are homeowner-specific parameters such as roof size, electricity consumption, and household income. When a homeowner approaches an installer for a proposal, they design to provide enough electricity to cover demand under ideal conditions, constrained by the roof size. To determine the price, the installer works within the constraints of the cost of installation and, determined during profit optimization procedure, the price-perwatt. Price-per-watt is multiplied by the total watt production of the system to calculate the price offered to the homeowner. If the homeowner accepts the proposal, then the project is installed. Regulatory agencies approve the project automatically.

Maintenance. During each model step, installed projects might experience failure according to the probability distribution specific to each PV panel design. The complexity of the failure is also subject to the probability distribution. Both determine the cost of maintenance that is specified in Eq. (12).

Reliability from Installer's Perspective. Unlike manufacturers, installers do not have perfect information on panel reliability (in the model). This is based on (a) conversations that authors' had with installers that suggested manufacturers' reliability statistics were sometimes unreliable and (b) reported solar panel failings, which are higher than warranty information would suggest. Additionally, reliability can vary with environmental conditions, such as solar radiation levels and grid stability. The installers must determine the reliability of two panels: (Current) the one they currently use and (New) the new one that a manufacturer offers them $\backslash$ each 
model cycle. For the current use panel they used the strategy described below.

Once the number of failures $n_{f}$, period from one failure to another $x_{f, i}$ for project $i$, and severity of failures $x_{c, i}$ are known to the installer it can update its internal estimate for the probability distribution for failures and their complexity.

It is assumed that reliability of the installation is exponentially distributed (it is standard distribution assumption for failure rates of the system).

$$
\lambda_{f} e^{-\lambda_{f} x}
$$

The installer agent does not know the exact parameter of the distribution of Eq. (15) but learns it by observing the performance of installed systems during the simulation. The prior distribution for parameter $\lambda_{f}$ is the Gamma distribution

$$
\frac{\beta_{f}^{\alpha_{f}}}{\Gamma\left(\alpha_{f}\right)} x^{\alpha_{f}-1} e^{-\beta_{f} x}
$$

Prior parameters $\alpha_{0, f}, \beta_{0, f}$ correspond to the optimistic assessment of an actual system reliability, such as estimated for the example [31], a study which investigated different sources and frequencies of PV module failures. To get some intuitive understanding for the parameter values in Appendix I it is possible to think about the prior values as describing a situation when 1 failure in 25 years is expected.

For assessing the reliability of new panels, we investigate the results of installers using one of three estimation strategies. (1- Optimistic) Installers assume that panels fail only once every twenty five years; ( 2 - Self) Installers estimate that the new panel will have the same reliability as their current panel, by their own assessment (Eq. 15); or (3 - Average) Installers estimate that the new panel will have a reliability equivalent to the average installer-reported reliability of the panels on the market now. Each of the scenarios is explored and results are presented in Section 4.

Regardless of the scenario, $\alpha_{f}$ and $\beta_{f}$ in Eq. (16) update with new information using standard formulas for Gamma distribution. The resulting posterior predictive for the expected time before the next failure follows a Pareto Type II distribution. Complexity of maintenance is assumed to have a normal distribution, with parameters $\mu_{\text {maint }}, \sigma_{\text {maint }}^{2}$. The prior distribution for these parameters is Normal-inverse-gamma with the parameters $\mu_{0}, v, \alpha, \beta$, updated using standard formulas. The resulting posterior predictive is

$$
t_{2 \alpha^{\prime}}\left(\tilde{x} \mid \mu^{\prime}, \frac{\beta^{\prime}\left(v^{\prime}+1\right)}{v^{\prime} \alpha^{\prime}}\right) .
$$

a non-standard t-distribution with scale and location parameter:

$$
X=\mu^{\prime}+\frac{\beta^{\prime}\left(v^{\prime}+1\right)}{v^{\prime} \alpha^{\prime}} T .
$$

Where $T \sim t_{\alpha^{\prime}}$, which is a standard t-distribution with $\alpha^{\prime}$ degrees of freedom.

Prior parameters for the distribution $\mu_{0}, v_{0}, \alpha_{0}, \beta_{0}$ are fixed at the levels given in Appendix I.
Installer Reputation. An installer's reputation relies on the uptime (productive energy creation) of their existing projects, as equipment failures result in downtime. Total production over all of an installer's projects, prod, is used to update estimates of reputation. The $\beta_{\text {rep }}$ scale parameter of the distribution is assumed to be fixed at the level 1.0. Prior value for parameter $\alpha_{r e p}$ of shape is 1.0. For every other period, except the initial, shape parameter is updated in the following way:

$$
\alpha_{t, \text { rep }}=1+\frac{1}{\frac{1}{\alpha_{t-1, \text { rep }}} \frac{N_{\text {per }}}{N_{\text {per }}+1}+\frac{\overline{\text { prod }_{t}}}{N_{\text {per }}+1}}
$$

Where

$$
\overline{\operatorname{prod}_{t}}=\frac{1}{N_{\text {projects }}} \sum_{i=1}^{N_{\text {projects }}} \operatorname{prod}_{t, i}
$$

is the average uptime production over all of an installer's projects. $N_{\text {per }}$ is the adjusted number of periods for estimation, which is equal to $n_{0}+t . t$ is the current period of the simulation and $n_{0}=10$ defines initial reputation "stickiness", meaning that realized failures affect estimated reputation with a weight of less than one.

\subsection{Manufacturer's decision process (passive)}

The manufacturer researches, designs, and prices new panels, represented by the model as passive actions following rules for pricing and exogenous speed of technological progress.

\subsubsection{Researching and designing new PV panels}

Every period each manufacturer updates their PV panel design, if their research efforts are fruitful. The design of the new panel begins with drawing a randomly-determined efficiency improvement, as well as expected reliability (time between failures) and maintenance complexity. This assumption is a significant simplification of an actual design for reliability. For examples and discussion of problems that face designers that focus on the problem of designing for reliability see [32]. Even a simplified model can still provide insights into optimal design choices by manufacturers, as argued in [33].

Efficiency, ef, improves over all manufacturers at an individual random rate, so that in the time period $t$ for each manufacturer

$$
e f_{t}=e f_{t-1} e^{\mu_{e f}+\sigma_{e f} \epsilon_{0,1}}
$$

and

$$
\epsilon_{0,1} \sim N(0,1)
$$

The efficiency of the new panel is known to the manufacturer and installer. Expected reliability is formed in the same way as expected efficiency, but is only known to the manufacturer (see Section 3.2.2 and Eq. (15) for installer's equations): 


$$
\lambda_{t}=\lambda_{t-1} e^{\mu_{\lambda}+\sigma_{\lambda} \epsilon_{0,1}}
$$

Generally, all panel design parameters can increase or decrease with each model step. The manufacturer decides to offer the panel to installers only if it offers a benefit over their existing offering, in terms of efficiency. Reliability does not affect this decision.

Expected maintenance costs, known only to the manufacturer, are $N\left(\mu_{\text {maint }}, \sigma_{\text {maint }}^{2}\right)$, and update with each model step in the same fashion as efficiency and reliability, with appropriate adjustment for multivariate generation. Let $\theta_{\text {maint }}=\left(\mu_{\text {maint }}, \sigma_{\text {maint }}^{2}\right)$ be the combination of parameters for distribution of maintenance costs. $\theta_{\text {maint }}$ is updated to new values in the following way:

$$
\begin{gathered}
\theta_{t, i, \text { maint }}=\theta_{t-1, i, \text { maint }} e^{\epsilon_{i, \text { maint }}} \\
\epsilon_{\text {maint }} \sim \boldsymbol{N}\left(\boldsymbol{\mu}_{\epsilon_{\text {maint }}}, \boldsymbol{\Sigma}_{\epsilon_{\text {maint }}}\right)
\end{gathered}
$$

Parameters of the distribution: $\mu_{e f}, \sigma_{e f}^{2}, \mu_{\lambda}, \sigma_{\lambda}^{2}, \boldsymbol{\mu}_{\epsilon_{\text {maint }}}$, $\boldsymbol{\Sigma}_{\epsilon_{\text {maint }}}$ are kept at the levels given in Appendix I.

\subsubsection{Manufacturer's pricing scheme}

The model assumes that initial prices are fixed and calculated based on the estimated price per efficiency unit using the following equations:

$$
\begin{gathered}
\text { price }_{\text {watt }}=0.65 \\
\text { price }_{\text {module,SEM }}=p_{\text {ricewatt }} N_{\text {watt }}
\end{gathered}
$$

where $N_{\text {watt }}$ pick production in watts under standard test conditions. After the initial period, price $_{\text {watt }}$ is decreases along a learning rate, which is assumed at $8 \%$, supported by data from [5].

\subsection{Homeowner's decision process}

In every model step, $10 \%$ of homeowners are randomly drawn to be contacted by one installer per homeowner. Installers present homeowners with a PV system proposal, which homeowners accept or not. The promised internal rate of return and installer's reputation guide this choice, which is also in-part determined by the income level of the homeowner. Higher income levels require lower levels of expected return, with the underlying assumption being that at a certain level of income, people choose PV systems for reasons other than financial, such as environmental concerns or propensity to be an early adopter. This nuance is included based on the results of the author's interviews with current PV system owners.

The probability of a homeowner accepting any given proposal is a logistic function with the following specification:

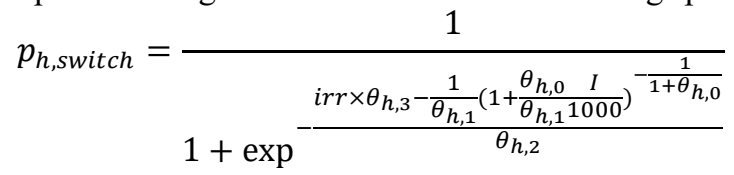

Figure 3 provides intuition regarding the response of this distribution to changes in income level and internal rates of return, from $\$ 10 \mathrm{~K}$ to $\$ 100 \mathrm{~K}$. Note that the threshold value of the required rate of return depends on the homeowner's income, $I$. Other parameters for the logistic function are maintained at the levels specified in Appendix I. Figure 4 illustrates response of distribution to changes in other parameters. Homeowners will make a decision to adopt PV if the promised rate of return is high enough, with the caveat that homeowners with higher levels of income require lower rates of return to consider adoption. Parameters in Eq. (28) control general slope of the function and the location of the switch point.

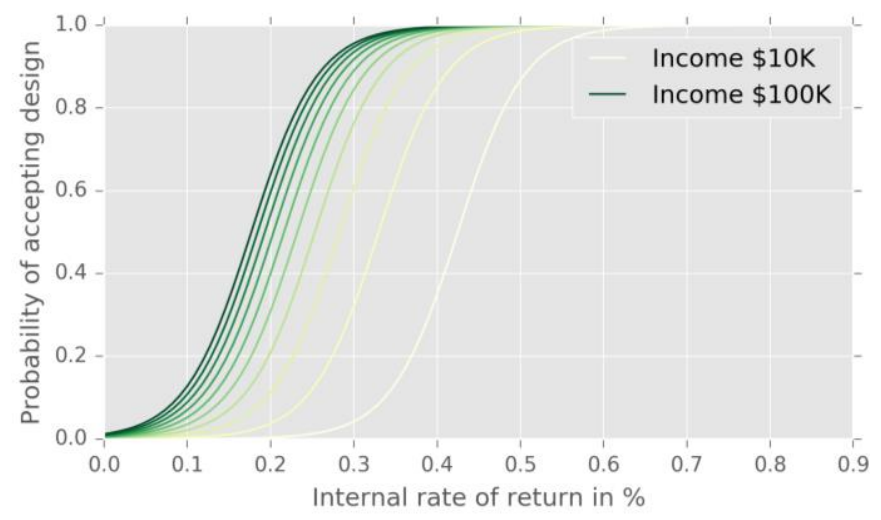

\section{FIGURE 3. PROBABILITY OF HOMEOWNER ACCEPTING PV PROPOSAL, GIVEN RATE OF RETURN (IRR) AND LEVEL OF INCOME}
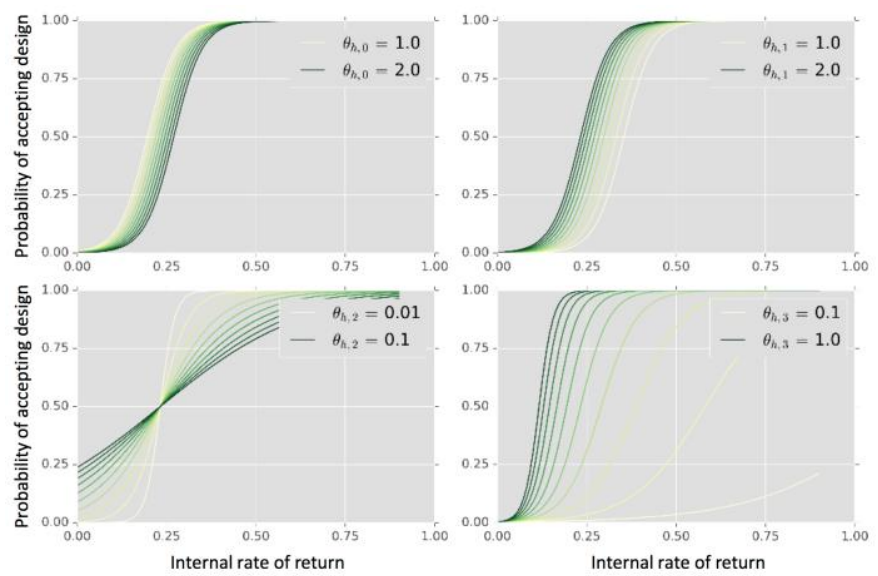

\section{FIGURE 4. PROBABILITY OF HOMEOWNER ACCEPTING PV PROPOSAL, GIVEN RATE OF RETURN (IRR) AND DIFFERENT LEVELS OF PARAMETERS}

From the homeowner's perspective, who does not know the reliability of the panel, the reputation of an installer $r e p_{i}$, is used to adjust expected rate of return for the offered design $i r r_{e}$. The resulting rate of return is $i r r_{e} \cdot r e p_{i}$. Under the assumptions of Section 3.2.2 and Eq. (19) reputation is calculated as a mean of the estimated distribution:

$$
r e p_{i}=\frac{1}{\alpha_{t, r e p}-1} \beta_{r e p}
$$


Internal rate of return is allowed to be negative in the model. $[0,1]$ range in the figures was chosen to simplify visual presentation. Negative internal rate could happen when savings on electricity bill are not offset to a high enough degree by the purchasing price of the PV system, or when net-metering prices will result in low realized savings.

Preferences parameters were set to represent past installation dynamics, for example from [1], given the observed rates of return on installed PV systems.

Other parameters that affect specific configuration of the proposed PV system installation are the homeowner's income, roof size, and electricity bill. These parameters are generated from the empirical distribution specified in the dataset Residential Energy Consumption Survey (RECS) conducted by U.S. Energy Information Administration [34]. RECS provides information about homeowners and renters, but in the model data only for homeowners was used.

\subsection{Model Calibration and Validation.}

When the available data is limited or, as is the current case, non-stationary, the choice between stronger validation or calibration has to be made. Limited historical data and fast changes that characterize the market do not provide enough information to permit simultaneous calibration and validation of results. In this work, the choice was made to give more weight to calibration efforts and less to validation of results.

The model was calibrated using multiple sources of information. Installer's profit function parameters were estimated based on the financial statements from SolarCity Corporation. Market size was inferred from the total number of installations given in [1]. Expected market shares were initiated at the level that describes equal split between installers. Incentives to explore and exploit were calibrated to reflect moderate risk aversion.

Manufacturer parameters that describe research into new panels were calibrated to replicate historical process for research, described in [5]. Parameters governing reliability of the panels were calibrated to match that observed in [35]. It should be noted that the research process for developing new panels is highly unpredictable for a time horizon over 5 years. While results of the simulation provide insights into market dynamics, their precision significantly decreases over time. Future prices for new PV panels were calibrated to match historical data and existing predictions, information in [5] was used to that purpose. Forecasts of PV panel prices beyond midterm horizon have wide error bands.

Homeowner preferences were calibrated to reflect current market returns on investment with adjustment for perceived risk of investing in PV panels. Physical and socio-economic parameters for homeowners were generated to replicate distributions given in RECS [34]. Electricity price was fixed at 15 cents per kilowatt hour, level of government incentive at $30 \%$, labor wage at $\$ 20$ per hours, and inflation rate at $2 \%$.

In general, parameters were subjected to sensitivity tests.. The model simulation results on the medium horizon were validated in a sense that they continue to observe past installation dynamics. But this type of model can be only validated in a limited way. The PV market is relatively young and rapidly developing, limiting amount and quality of information available for validation and calibration.

\section{RESULTS AND DISCUSSION}

The agent-based model was run for each scenario (CA, MA) under a number of different conditions, and for 15-year cycles. For each scenario, there were 7 manufacturers, 3 installers, and 1000 homeowners. The number of installers was fixed at the historical levels for the number of "big" installers in the market. It is assumed that small installers will mimic strategies of the big ones. Each 15-year run took 5 minutes to complete. Each run was completed 100 times using different seeds. $\mathrm{C}++$ was used to create custom program and run the model. Results presented here are an average of those runs.

There are three main indicators which give a sense of market conditions over the years:

1) Hit \%. Percent of homeowners that adopt a PV system each year. Note that Hit $\%$ is constrained to a maximum of $10 \%$, the number of homeowners approached by installers each year. Hit $\%$ indicates $P V$ penetration for a given year.

2) Accumulated $\%$ Installations, Total Number of Installations. The percentage (or number) of all the homeowners that have ever installed PV systems on their roof, which indicates the accumulated PV penetration level.

3) Price per Watt. The average purchase price per watt for systems installed in a given year.

There are two additional indicators that are useful to follow, while noting that they are partially determined by model parameters, as indicated in Section 3.1:

4) Efficiency. Efficiency is the percentage of energy from the sun that a panel converts into electricity. The efficiency of modern panels in the US currently hovers around $20 \%$.

5) Reliability. In the results, reliability is reported as the number of years with one failure, from the manufacturer's point of view (as opposed to the installers' and homeowners' estimates). For example, a reliability of " 20 " means that the panel is predicted to fail once in 20 years.

An overview of the market behavior is shown in Figure 5. Hit \%, for both CA and MA, fluctuates year over year and does not show a definitive trend, although it seems to in general decrease for CA however peak and then decline for MA. The total number of installations trends slightly higher in the CA scenario compared to MA. For both scenarios, penetration level increases to around $14 \%$ by the end of the simulation. Overall, roof sizes present a physical limitation on the number of possible effective installations, but this should be at least partially offset by increases in panel efficiency, which decrease the effective size of installations. 


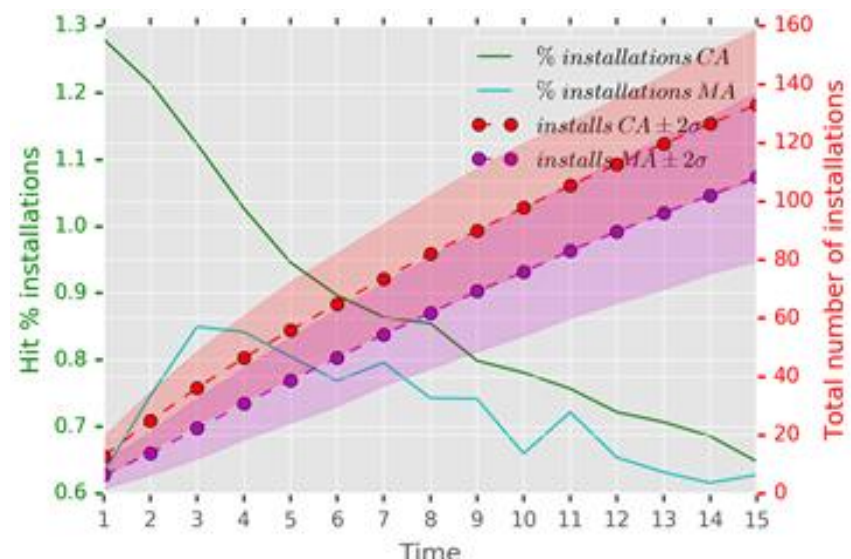

FIGURE 5. OVERALL MARKET BEHAVIORS IN BOTH CA AND MA SCENARIOS

Figure 6 shows that efficiency increases over time. It presents the three different scenarios that installers can use to gauge panel reliability: market average, same-as-current offering, and optimistic. While these three strategies do affect the actual reliability of the panels offered by manufacturers, the strategies have no effect on the push for efficiency. Manufacturers have a strong tendency to switch to designs with a higher level of efficiency, evident from the upward trend in efficiency presented in the figure. Installers that are explorers (er) and exploiters (el) both pursue panels with higher levels of efficiency, as effects of lower reliability are very limited. Installer reputation has little effect on homeowner decisions. The growing market provides a good incentive for adopting new technology and decreases its risks.

Thus, when the benefits of improving efficiency are wellknown to all market participants, and the knowledge (or reality) of system-failure is low, it pays for manufacturers to invest in efficiency improvements. For installers, it is better to pursue an exploration strategy when benefits are high and general risk levels are low-even for installers assigned to prefer an exploitation strategy. This is a promising model behavior, as it matches both intuition and actual industry performance.

Figure 7 presents results for price-per-watt dynamics and penetration level by income category and by level of electricity consumption in the CA scenario. It can be observed that the Hit $\%$ decreases gradually while price per watt remains steady. Homeowners with more income and electricity consumption make up the majority of that opt to install.

The simulated results for MA scenario are shown in Figure 8. Over time, partially-controlled by parameterization, priceper-watt remains stable in CA scenario but decreases in MA scenario. Prices stabilize at higher levels in CA scenario as compared to the MA case. High CA energy prices allow homeowners to accept higher prices and still receive reasonable return on their investment. In the MA scenario, price-per-watt stabilizes at lower levels than in CA, because less solar energy means homeowners require a higher rate of return.
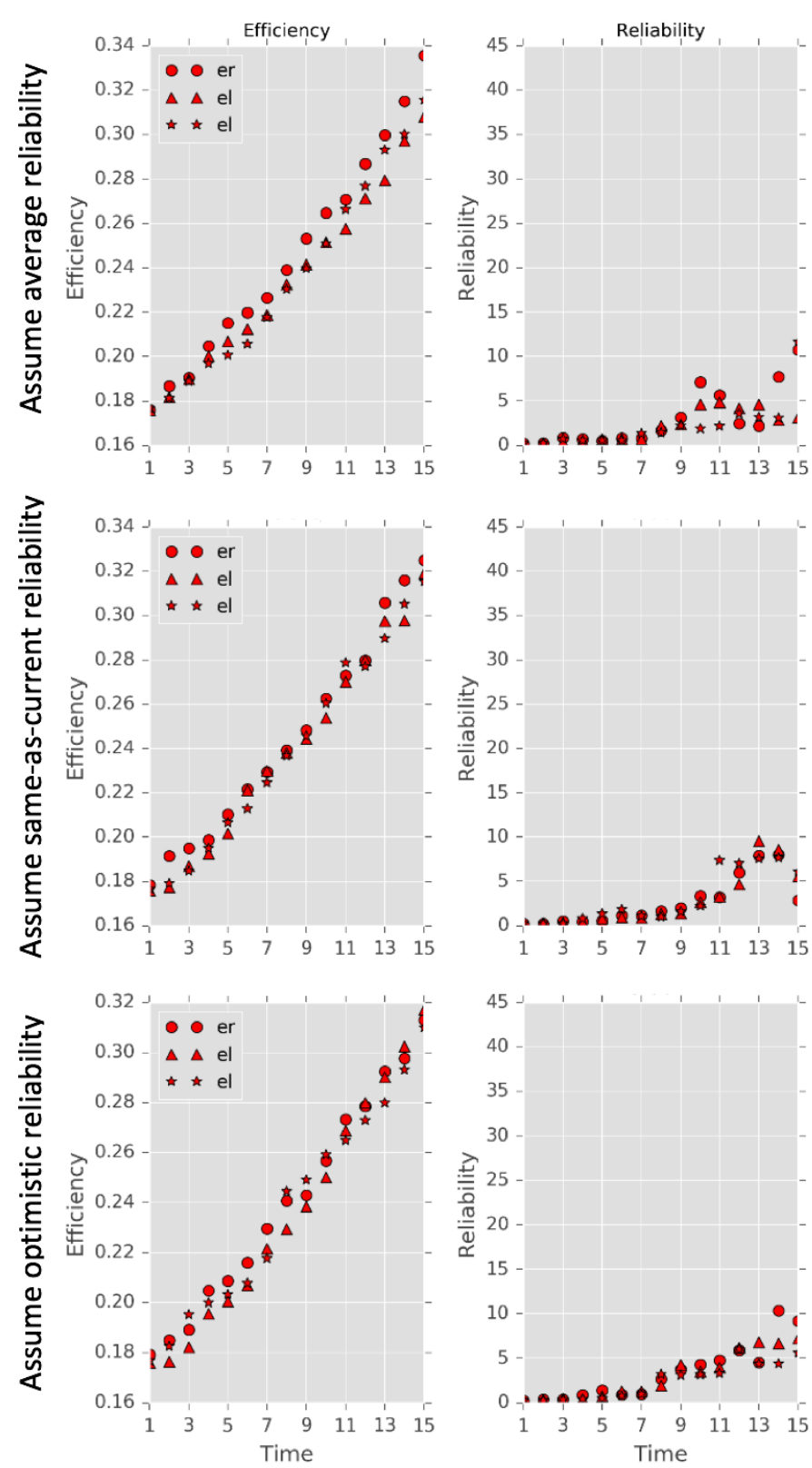

FIGURE 6. (CA SCENARIO) THREE APPROACHES TO ESTIMATING PANEL RELIABILITY AND THE EFFICIENCY CHOICES INSTALLERS MAKE

Agent-based modeling allows us to look at the dynamics of penetration level by income group and electricity bill. As results in Figure 7 and Figure 8 are averaged across simulation runs with different seeds, it is instructional to investigate the general dynamics of increasing penetrations shares for higher income and electricity bills groups. Each bar in Figure 8 below, for example, has lower income (electricity bill) groups at the bottom and high income (electricity bill) at the top. It is of no surprise that relative penetration level is much higher for high income groups and those families that have high electricity bills for both CA and MA scenarios. 


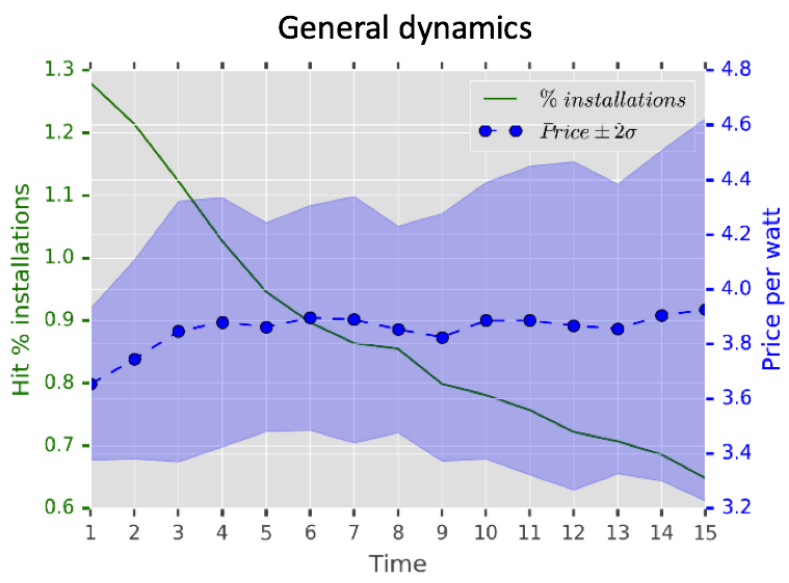

Penetration level
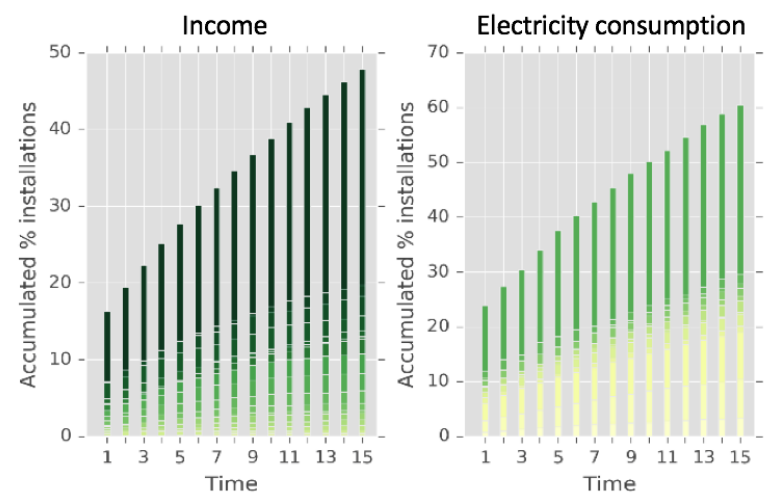

FIGURE 7. (CA SCENARIO) THE CHANGES OF HIT \%, PRICE PER WATT (ABOVE), AND ACCUMULATED \% INSTALLATIONS (BELOW) OVER TIME

\section{CONCLUSION}

The matrix in Figure 9 summarizes, in qualitative form, the sensitivity analysis results of the model. All factors that have influence on the current penetration level ("immediate characteristics") or expected future sales could be divided into different categories, such as physical characteristics (including design characteristics), market characteristics and preferences characteristics.

We explicitly model the design parameters of the solar PV systems as their efficiency and reliability. We find that efficiency dynamics shape the market outcomes the most, while reliability parameters only guide some of the decision-making with less profound effect. Maintenance costs, tied to the reliability of the system, do not represent a major decision factor for homeowners or installers, due to relative rarity of maintenance events and their low-cost impacts.

We also find that the roof sizes introduce restrictions on the possible system sizes and, as such, potential market sizes. But this can be partially-mitigated by improvements in panel efficiency. Changes in the level of solar irradiation, as exhibited in CA vs. MA scenarios, alters the realized market price-perwatt. In both scenarios, the tendency to follow exploration strategy dominates.
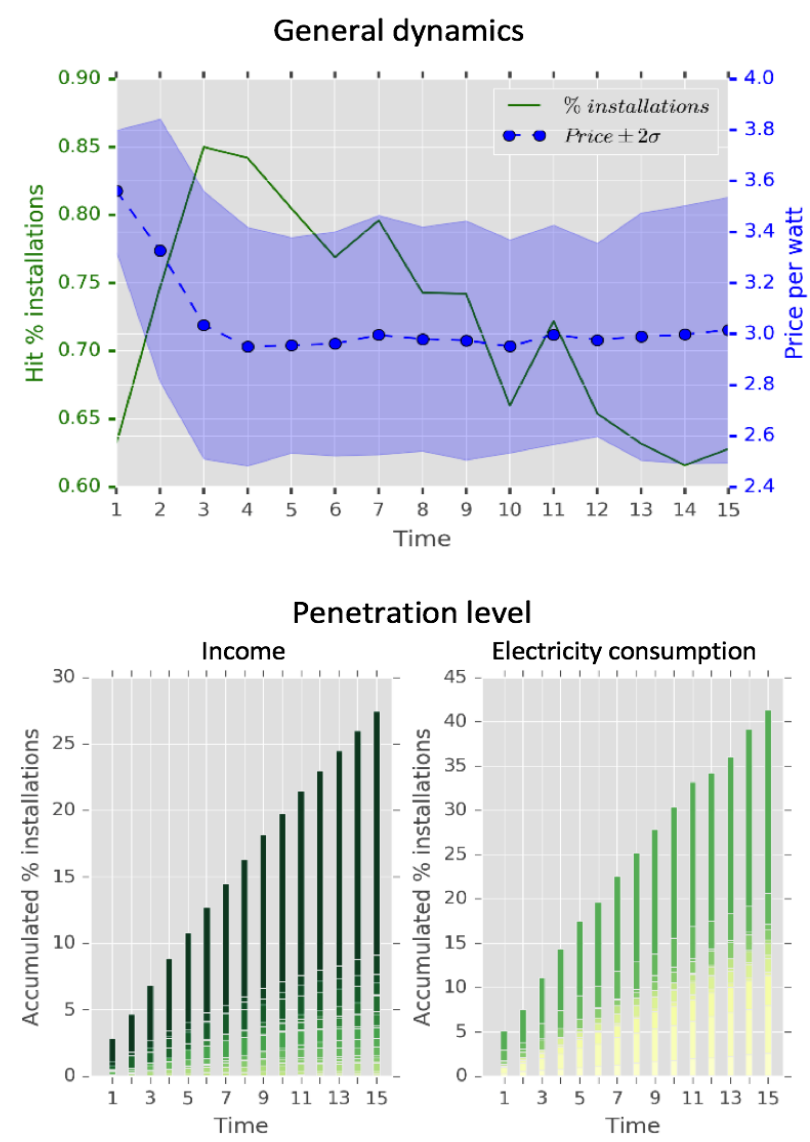

FIGURE 8. (MA SCENARIO) THE CHANGES OF HIT \%, PRICE PER WATT (ABOVE), AND ACCUMULATED \% INSTALLATIONS (BELOW) OVER TIME

As for market characteristics, the potential market size determines financial viability of any strategy and thus is important to the decision-making agents. However, costs (hard and soft) are more important factors since they directly decide the expenses and determine the profitability of the systems and at what price point. Hard costs are particularly important in the analyzed scenarios, representing the economics of currentlyavailable panels. This explains why installers track efficiency levels so closely. Also important are the model's assumptions on the preferences of installers (exploration vs. exploitation) or homeowners (rates of return on investment). Future work will explore more sophisticated models here.

As the model cycles to maturity, the dynamics of the balance between exploration and exploitation change and the reliability are weighted more-heavily by homeowners. Another factor that continues to shape these dynamics are low-price, low-quality competition from manufacturers that specialize in such systems. Observed dominance of the efficiency of the panel in the decision-making is thus the result of both model assumptions and the existing cost and information structure of the market. 


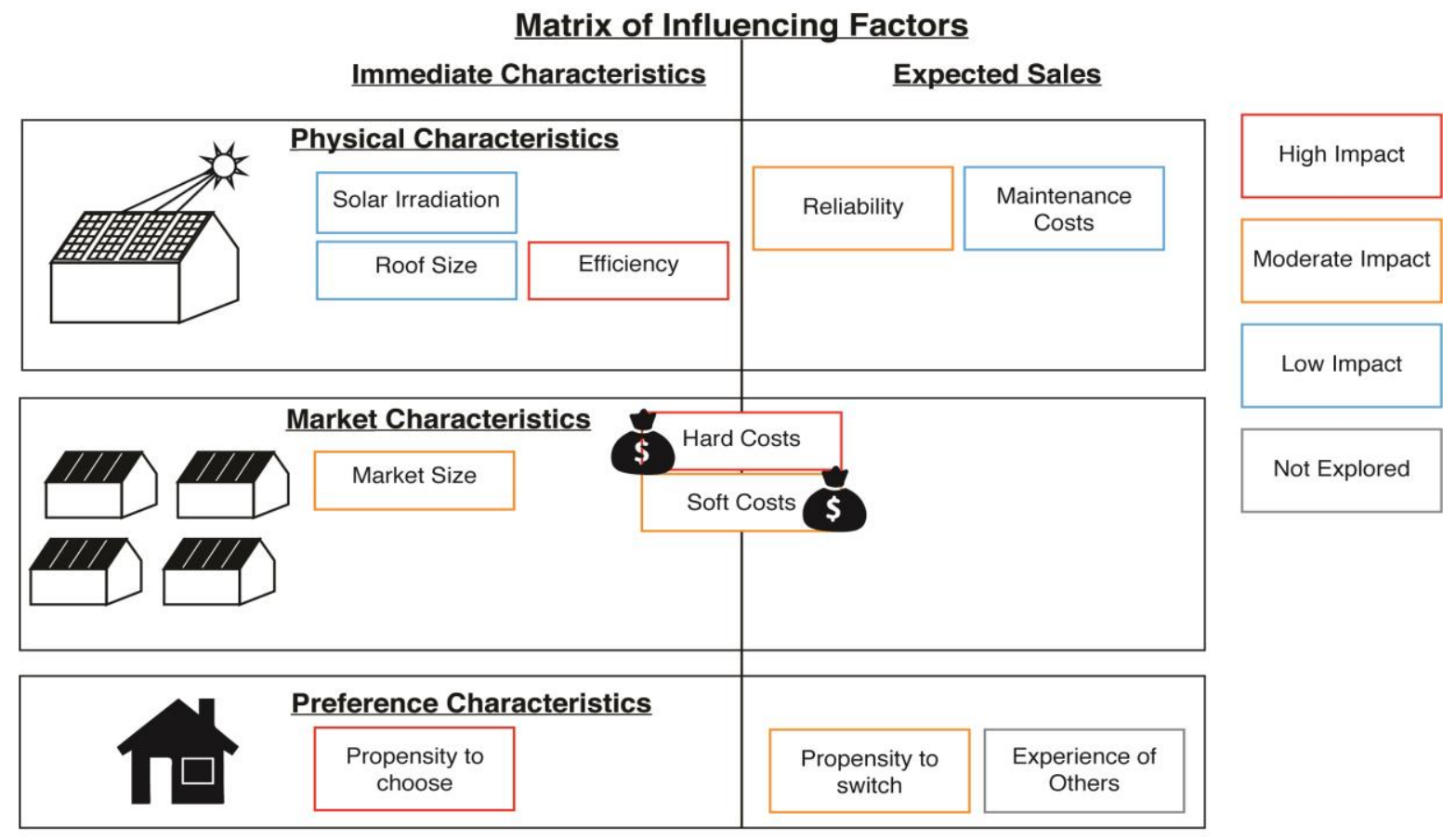

FIGURE 9. FACTORS THAT DETERMINE MARKET OUTCOMES IN THE PRESENCE OF DIFFERENT DECISION PROCESSES

The assumptions and generalizations do impose limitations on the implications of the work. These include not explicitly modelling manufacturers' research priorities. Explicit modeling of these might change the unanimous dominance of the efficiency as a major deciding-factor for installers. Restrictions on choice also limit conclusions. For example, installers can only consider one manufacturer each cycle, and homeowners can only consider one installer, who offers only one panel type, each cycle. These choice restrictions provide clarity on the agent-based model conclusions, with too many "moving parts," it is difficult to perform basic validation of the results and explore high-level trends, as presented here. As the basic behavior is now intuitively validated as reasonable, future versions of the model will provide more choice options.

Another potential issue lies with imposing specific functional forms on the reliability and complexity distributions. While assumptions made in the paper are conservative, it could be argued that investigation of other possible approaches might be advisable. There are also limitations of the selection procedure employed by the installer for choosing potential PV panels for new proposals. But it is unclear if more explicit modeling of this procedure would alter the results, while the level of model complexity would significantly increase.

To summarize, the analysis investigated the dynamics of PV system penetration in the US residential solar energy market using an agent-based model. In particular, it focused on the intermediary agent of installers, which was articulated in the model as guiding design developments of $\mathrm{PV}$ panels, rather than the more traditional approach of directly modeling homeowners as guiding these developments through their preferences / choices. The model articulated the installer's decision process as one of exploration vs. exploitation, while maximizing their profits. Whether exploration or exploitation technology adoption strategies dominates depends on the specifics of the market, such as effect of reputation, which was possibly underrepresented in the model.

As represented, the installers explore new panel offers more than they exploit existing, and this drives technological development (panel efficiency). This has potential implications for policy-makers at the state and national level, if policies can alleviate risks from new panel technologies, perhaps by financially compensating homeowners for system downtime, efficiency should be highly-sought over reliability, which would be a boon to the progress of the solar industry.

\section{ACKNOWLEDGMENTS}

This research is based upon work supported by the National Science Foundation under Grant No. 1363254. Any opinions, findings, and conclusions or recommendations expressed in this material are those of the authors and do not necessarily reflect the views of the National Science Foundation.

\section{REFERENCES}

[1] Millstein, D., Cates, S., Disanti, N., Widiss, R., Barbose, G., and Darghouth, N., 2016, Tracking the Sun IX The Installed Price of Residential and Non-Residential Photovoltaic Systems in the United States, Berkeley.

[2] "SunShot Initiative" [Online]. Available: 
https://energy.gov/eere/sunshot/sunshot-initiative.

[Accessed: 10-Feb-2017].

[3] "SolarCity Laying off Workers, Restructuring" [Online]. Available:

http://www.mercurynews.com/2016/08/17/solarcity-layingoff-workers-restructuring/. [Accessed: 10-Feb-2017].

[4] Chen, H. Q., Honda, T., and Yang, M. C., 2013,

"Approaches for Identifying Consumer Preferences for the Design of Technology Products: A Case Study of Residential Solar Panels,” J. Mech. Des., 135(6), p. 61007.

[5] Woodhouse, M., Jones-Albertus, R., Feldman, D., Fu, R., Horowitz, K., Chung, D., Jordan, D., and Kurtz, S., 2016, On the Path to SunShot: The Role of Advancements in Solar Photovoltaic Efficiency, Reliability, and Costs, Golden, CO.

[6] Chung, D., Horowitz, K., and Kurup, P., 2016, On the Path to SunShot: Emerging Opportunities and Challenges in U.S. Solar Manufacturing, Golden, CO.

[7] Gomez, K., Sinitskaya, E., Bao, Q., MacDonald, E., and Yang, M., 2017, "Designing Linked Journey Maps to Understand the Complexities of the Residential Solar Energy Market," Available:

https://erinmacd.stanford.edu/Publications.html.

[8] Karakaya, E., and Sriwannawit, P., 2015, "Barriers to the Adoption of Photovoltaic Systems: The State of the Art," Renew. Sustain. Energy Rev., 49, pp. 60-66.

[9] Islam, T., and Meade, N., 2013, "The Impact of Attribute Preferences on Adoption Timing: The Case of Photo-Voltaic (PV) Solar Cells for Household Electricity Generation," Energy Policy, 55, pp. 521-530.

[10] Wu, J., Botterud, A., Mills, A., Zhou, Z., Hodge, B. M., and Heaney, M., 2015, "Integrating Solar PV (Photovoltaics) in Utility System Operations: Analytical Framework and Arizona Case Study," Energy, 85, pp. 1-9.

[11] Wilkerson, J. T., Cullenward, D., Davidian, D., and Weyant, J. P., 2013, "End Use Technology Choice in the National Energy Modeling System (NEMS): An Analysis of the Residential and Commercial Building Sectors," Energy Econ., 40, pp. 773-784.

[12] Janko, S. A., Gorman, B. T., Singh, U. P., and Johnson, N. G., 2015, "High Penetration Residential Solar Photovoltaics and the Effects of Dust Storms on System Net Load," Proc. ASME 2015 Int. Des. Eng. Tech. Conf. Comput. Inf. Eng. Conf., (57076), p. V02AT03A033.

[13] Frischknecht, B. D., and Whitefoot, K. S., 2014, "Market Simulation Based Sensitivity Analysis as a Means to Inform Design Effort as Applied to Photovoltaic Panels," J. Mech. Des., 136, p. 54501.

[14] Tesfatsion, L., 2006, "Handbook of Computational Economics," pp. 831-880.

[15] Henry, A. D., and Vollan, B., 2014, "Networks and the Challenge of Sustainable Development," Annu. Rev. Environ. Resour., 39, pp. 583-610.

[16] Zhao, J., Mazhari, E., Celik, N., and Son, Y.-J., 2011, "Hybrid Agent-Based Simulation for Policy Evaluation of Solar Power Generation Systems," Simul. Model. Pr. Th., 19, pp. 2189-2205.

[17] Robinson, S. A., and Rai, V., 2015, "Determinants of Spatio-Temporal Patterns of Energy Technology Adoption: An Agent-Based Modeling Approach,” Appl. Energ., 151, pp. $273-284$.

[18] Zhang, H., Vorobeychik, Y., Letchford, J., and Lakkaraju, K., 2015, "Data-Driven Agent-Based Modeling, with Application to Rooftop Solar Adoption," Proc. 2015 Int. Conf. Auton. Agents Multiagent Syst., pp. 513-521.

[19] Palmer, J., Sorda, G., and Madlener, R., 2015, "Modeling the Diffusion of Residential Photovoltaic Systems in Italy: An Agent-Based Simulation," Technol. Forecast. Soc. Change, 99, pp. 106-131.

[20] Mashhadi, A. R., Esmaeilian, B., and Behdad, S., 2016, "Simulation Modeling of Consumers' Participation in Product Take-Back Systems," J. Mech. Des., 138(5), pp. 51403-51411.

[21] Rai, V., and Henry, A. D., 2016, "Agent-Based Modelling of Consumer Energy Choices," Nat. Clim. Chang., (6), pp. $556-562$.

[22] “U.S. Solar Resource Maps" [Online]. Available: http://www.nrel.gov/gis/solar.html. [Accessed: 10-Feb2017].

[23] Wilson, C., and Dowlatabadi, H., 2007, "Models of Decision Making and Residential Energy Use," Annu. Rev. Environ. Resour., 32, pp. 169-203.

[24] Sinitskaya, E., and Tesfatsion, L., 2015, "Macroeconomies as Constructively Rational Games," J. Econ. Dyn. Control, 61, pp. 152-182.

[25] Foster, A. D., and Rosenzweig, M. R., 2010, "Microeconomics of Technology Adoption," Annu. Rev. Econom., 2, pp. 395-424.

[26] Jara-Ettinger, J., Gweon, H., Schulz, L. E., and Tenenbaum, J. B., 2016, "The Naïve Utility Calculus: Computational Principles Underlying Commonsense Psychology," Trends Cogn. Sci., 20(8), pp. 589-604.

[27] Gill, J., 2014, Bayesian Methods: A Social and Behavioral Sciences Approach, CRC press.

[28] Bubeck, S., and Cesa-Bianchi, N., 2012, "Regret Analysis of Stochastic and Nonstochastic Multi-Armed Bandit Problems," arXiv Prepr. arXiv1204.5721.

[29] Szepesvári, C., 2010, "Algorithms for Reinforcement Learning,” Synth. Lect. Artif. Intell. Mach. Learn., 4(1), pp. $1-103$.

[30] Meyer J W, R., 2016, “(When) Are We Dynamically Optimal? A Psychological Field Guide for Marketing Modelers," J. Mark., 80(5), pp. 20-33.

[31] International Energy Agency, 2014, IEA-PVPS T13-01 2014 Review of Failures of Photovoltaic Modules Final.

[32] Paulson, E. J., and Starkey, R. P., 2013, "Development of a Multistage Reliability-Based Design Optimization Method," J. Mech. Des., 136(1), p. 11007.

[33] Smith, W. F., Millisavijevic, J., Sabeghi, M., Allen, J. K., and Mistree, F., 2015, "The Realization of Engineered Systems With Considerations of Complexity," Proc. ASME 2015 Int. Des. Eng. Tech. Conf. Comput. Inf. Eng. Conf., (57175), pp. 1-11.

[34] U.S. Energy Informattion Administration, 2009, "Residential Energy Consumption Survey" [Online]. Available: http://www.eia.gov/consumption/residential/. [Accessed: 10-Feb-2017].

[35] International Energy Agency, 2014, Review of Failures of Photovoltaic Modules Final. 


\section{NOMENCLATURE}

\begin{tabular}{|c|c|c|}
\hline PV & Photovoltaic & \multirow{2}{*}{$a_{d}$} \\
\hline$N_{\text {market }}$ & Market size & \\
\hline$N_{\text {panels }}$ & Number of panels in PV system & \multirow{2}{*}{$\alpha_{f}$} \\
\hline$N_{\text {per }}$ & Number of periods for estimating reputation. & \\
\hline$N_{\text {projects }}$ & Number of active projects for installer & $\alpha_{t, r e p}$ \\
\hline$N_{\text {watt }}$ & STC power rating for $\mathrm{PV}$ module & \multirow[t]{2}{*}{$\beta$} \\
\hline$T_{\text {forecast }}$ & Forecasting horizon for expected profit & \\
\hline$V_{0, \theta}$ & $\begin{array}{l}\text { Bayesian prior for the variance of the } \\
\text { distribution for demand function }\end{array}$ & $\beta_{0}$ \\
\hline$Z_{0, \text { inst }}$ & Prior values for demand function estimation & $\beta_{0, f}$ \\
\hline$b_{0, d}$ & $\begin{array}{l}\text { Initial value for parameter for prior for demand } \\
\text { function distribution }\end{array}$ & $\beta_{f}$ \\
\hline$b_{d}$ & $\begin{array}{l}\text { Parameter of a Bayesian prior of the demand } \\
\text { function distribution }\end{array}$ & $\begin{array}{l}\beta_{\text {rep }} \\
\theta_{\text {administration }}\end{array}$ \\
\hline$c_{\text {administration }}$ & Administrative costs for installer & $\theta_{\text {complexity install }}$ \\
\hline$c_{\text {design }}$ & Cost of designing PV system & $\theta_{\text {design }}$ \\
\hline$c_{\text {installation }}$ & Costs of installing PV system & \multirow{2}{*}{$\theta_{i, e}$} \\
\hline$c_{\text {maintenance }}$ & Maintenance costs for installer & \\
\hline$c_{\text {materials }}$ & Cost of material for PV system & $\theta_{\text {marketing }}$ \\
\hline$c_{\text {marketing }}$ & Marketing costs for installer & \multirow{2}{*}{$\theta_{\text {permit general }}$} \\
\hline$c_{\text {permit }}$ & Cost of obtaining permits for PV system & \\
\hline \multicolumn{2}{|c|}{$C_{t+\tau}\left(p(\right.$ maintenance $\left.),\{q\}_{T_{0}}^{t+\tau}\right)$} & $\theta_{\text {permit specific }}$ \\
\hline$e f_{0}$ & Initial level of efficiency & $\theta^{d}$ \\
\hline$e f_{t}$ & Efficiency of a PV module & \multirow{2}{*}{$\begin{array}{l}\theta_{h, i} \\
\lambda_{0} \\
\lambda_{f}\end{array}$} \\
\hline$f_{c}\left(\{q\}_{T_{0}}^{t+\tau}, p\right.$ (maint & $\begin{array}{ll}\text { zance)) } & \begin{array}{l}\text { Estimated labor costs of } \\
\text { maintenance }\end{array}\end{array}$ & \\
\hline $\operatorname{irr}_{i}$ & $\begin{array}{l}\text { Internal rate of return offered by design by firm } \\
i\end{array}$ & $\mu$ \\
\hline$i r r_{-i}$ & $\begin{array}{l}\text { Internal rate of return offered by design by other } \\
\text { firms }\end{array}$ & $\mu_{0}$ \\
\hline$n_{0}$ & Parameter for reputation stickiness & \multirow{2}{*}{$\mu_{0, \text { maint }}$} \\
\hline$n_{f}$ & Number of failures & \\
\hline$p_{\text {inst }, \text { switch }}$ & $\begin{array}{l}\text { Probability of switching to new design for } \\
\text { installer }\end{array}$ & $\mu_{0, \theta}$ \\
\hline$p($ maintenance $)$ & $\begin{array}{l}\text { Probability distribution for expected } \\
\text { maintenance costs given current and expected } \\
\text { portfolio of projects }\end{array}$ & $\begin{array}{l}\mu_{e f} \\
\mu_{\text {maint }}\end{array}$ \\
\hline $\begin{array}{l}p_{h, \text { switch }} \\
\text { price }\end{array}$ & $\begin{array}{l}\text { Probability of accepting design for homeowner } \\
\text { Price of a PV system }\end{array}$ & $\boldsymbol{\mu}_{\epsilon_{\text {maint }}}$ \\
\hline price $_{\text {module,SEM }}$ & Manufacturer's price of a PV module & $\mu_{\lambda}$ \\
\hline $\begin{array}{l}\operatorname{price}_{w a t t} \\
\operatorname{prod}_{t, i}\end{array}$ & $\begin{array}{l}\text { Price per watt for PV module } \\
\text { Production for project } \mathrm{i} \text { in time } \mathrm{t}\end{array}$ & $\sigma_{0, \text { maint }}^{2}$ \\
\hline$q_{t+\tau}($ price $)$ & $\begin{array}{l}\text { Demand for current design at time } t+\tau \text { for } \\
\text { price } \mathrm{p}\end{array}$ & \multirow[t]{2}{*}{$\begin{array}{l}\sigma_{e f}^{2} \\
\sigma_{\text {maint }}^{2}\end{array}$} \\
\hline $\operatorname{rep}_{i}$ & Reputation of a firm i & \\
\hline $\operatorname{rep}_{-i}$ & Reputation of other firms & $\sigma_{\lambda}^{2}$ \\
\hline$w_{t}$ & Prevailing labor wage & \multirow[t]{2}{*}{$v$} \\
\hline$Z_{\text {inst }}$ & Demand function parameters & \\
\hline$\alpha$ & $\begin{array}{l}\text { Parameter of a Bayesian prior for probability } \\
\text { distribution for maintenance }\end{array}$ & \multirow[t]{2}{*}{$v_{0}$} \\
\hline$\alpha_{0}$ & $\begin{array}{l}\text { Initial value for prior for probability distribution } \\
\text { for maintenance }\end{array}$ & \\
\hline$a_{0, d}$ & $\begin{array}{l}\text { Initial value for parameter for prior for demand } \\
\text { function distribution }\end{array}$ & \multirow{2}{*}{$\begin{array}{l}x_{f, i} \\
\boldsymbol{\Sigma}_{\epsilon_{\text {maint }}}\end{array}$} \\
\hline$\alpha_{0, f}$ & Initial value for prior for failure distribution & \\
\hline
\end{tabular}

Parameter of a Bayesian prior for demand function distribution

Parameter of a Bayesian prior for failure distribution

Parameter of installer reputation at time $t$

Parameter of a Bayesian prior for probability distribution for maintenance

Initial value for prior for probability distribution for maintenance

Initial value for prior for failure distribution

Parameter of a Bayesian prior for failure distribution

Fixed in time parameter of installer reputation

Parameter for administrative costs

Parameter for complexity of installation

Parameter for design costs

Parameter values for explorer/exploiter decision process

Parameter for marketing costs

Parameter for cost estimation of permitting, general part

Parameter for cost estimation of permitting, design specific part

Parameters of an estimated demand function

Parameter i of homeowner's decision function

Initial value for reliability

Parameter for failure distribution

Parameter of a Bayesian prior for probability distribution for maintenance

Initial value for prior for probability distribution for maintenance

Initial value for parameters for complexity of maintenance distribution

Bayesian prior for the mean of the distribution for demand function

Parameter for efficiency distribution

Parameter of probability distribution for maintenance

Parameters for complexity of maintenance distribution

Parameter for reliability distribution

Initial value for parameter for complexity of maintenance distribution

Parameter for efficiency distribution

Parameter of probability distribution for maintenance

Parameter for reliability distribution

Prior for parameter of probability distribution for maintenance

Initial value for prior for parameter of probability distribution for maintenance

Total expected future profit at time $t$

Complexity of the failure

Time between failures for project $\mathrm{i}$

Parameters for complexity of maintenance distribution 


\section{APPENDIX I}

Parameter values for the model.

\begin{tabular}{|c|c|}
\hline Parameter & Value \\
\hline \multicolumn{2}{|c|}{$\begin{array}{l}\text { Initial parameter values for the installer's } \\
\text { demand estimation procedure. }\end{array}$} \\
\hline$\mu_{0, \theta}$ & $\begin{array}{c}(-0.002375 \\
5.9375 \\
0.002375 \\
-2.375 \\
-0.002375)\end{array}$ \\
\hline$V_{0, \theta}$ & $0.5 I_{6}$ \\
\hline$a_{0, \mathrm{~d}}$ & 1.0 \\
\hline$b_{0, \mathrm{~d}}$ & 1.0 \\
\hline$Z_{0, \text { inst }}$ & $(1.0,0.1,1.0,0.1,1.0)$ \\
\hline$N_{\text {market }}$ & 50000 \\
\hline \multicolumn{2}{|c|}{$\begin{array}{l}\text { Parameter values for the installer's decision } \\
\text { procedure: cost function. }\end{array}$} \\
\hline$\theta_{\text {complexity install }}$ & 100 \\
\hline$\theta_{\text {design }}$ & 350 \\
\hline$\theta_{\text {permit general }}$ & 200 \\
\hline$\theta_{\text {permit specific }}$ & 50 \\
\hline$\theta_{\text {administration }}$ & 2000000 \\
\hline$\theta_{\text {marketing }}$ & 2500000 \\
\hline \multicolumn{2}{|c|}{$\begin{array}{c}\text { Parameter values for the installer's } \\
\text { decision procedure: propensities to switch. }\end{array}$} \\
\hline$\theta_{0, \text { explorer }}$ & 1 \\
\hline$\theta_{1, \text { explorer }}$ & 0.25 \\
\hline$\theta_{0, \text { exploiter }}$ & 1.5 \\
\hline$\theta_{1, \text { exploiter }}$ & 0.5 \\
\hline \multicolumn{2}{|c|}{$\begin{array}{l}\text { Parameter values for the installer's } \\
\text { decision procedure: priors for reliability } \\
\text { distribution. }\end{array}$} \\
\hline$\alpha_{0, f}$ & 1 \\
\hline$\beta_{0, f}$ & 25 \\
\hline \multicolumn{2}{|c|}{$\begin{array}{l}\text { Parameter values for the installer's } \\
\text { decision procedure: priors for complexity } \\
\text { distribution. }\end{array}$} \\
\hline$\mu_{0}$ & 50 \\
\hline$v_{0}$ & 1 \\
\hline$\alpha_{0}$ & 1 \\
\hline$\beta_{0}$ & 50 \\
\hline \multicolumn{2}{|c|}{$\begin{array}{l}\text { Parameter values for the design of PV panel } \\
\text { for manufacturers. }\end{array}$} \\
\hline$\mu_{e f}$ & 0.01 \\
\hline$\sigma_{e f}^{2}$ & 0.01 \\
\hline$e f_{0}$ & 0.16 \\
\hline$\mu_{\lambda}$ & 0.01 \\
\hline$\sigma_{\lambda}^{2}$ & 0.01 \\
\hline$\lambda_{0}$ & 0.2 \\
\hline
\end{tabular}

\begin{tabular}{|c|c|}
\hline $\boldsymbol{\mu}_{\boldsymbol{\epsilon}_{\text {maint }}}$ & $(0.0,0.0)$ \\
\hline $\boldsymbol{\Sigma}_{\boldsymbol{\epsilon}_{\text {maint }}}$ & {$\left[\begin{array}{ll}0.01 & 0.01 \\
0.01 & 0.02\end{array}\right]$} \\
\hline$\mu_{0, \text { maint }}$ & 160 \\
\hline$\sigma_{0, \text { maint }}^{2}$ & 400 \\
\hline \multicolumn{2}{|c|}{ Parameter values for the homeowner's } \\
decision procedure. \\
\hline$\theta_{h, 0}$ & 1.5 \\
\hline$\theta_{h, 1}$ & 2 \\
\hline$\theta_{h, 2}$ & 0.02 \\
\hline$\theta_{h, 3}$ & 0.5 \\
\hline
\end{tabular}

